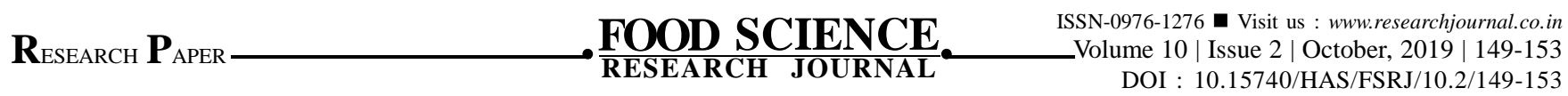

\title{
Development of value added product with ragi and analyze the mineral content
}

\begin{abstract}
Anamika Gautam and $V_{\text {andana }} \mathrm{S}_{\text {ati }}$
Finger millet or ragi is one of the ancient millets in India (2300 BC). Of all the cereals and millets, finger millet has the highest amount of calcium (344 $\mathrm{mg} \%$ ) and potassium (408 $\mathrm{mg} \%$ ). It has higher dietary fibre, minerals and sulfur containing amino acids compared to white rice, the current major staple in India. The present study was carried out with objective to develop fortified mathri using non-germinated and germinated ragi flour and assess the organoleptic acceptability and analyze the mineral content (calcium, phosphorus and iron) of developed products. Ragi provides highest level of calcium, antioxidants properties, phytochemicals, which makes it easily and slowly digestible. Hence, it helps to control blood glucose levels in diabetic patients very efficiently. The recipe was standardized and subjected to organoleptic evaluation by a panel of semi-trained judges using 9-point hedonic scale. The overall organoleptic acceptability of the control mathri was $7.0 \pm 1$ and the mean score of developed mathri 20 per cent and 30 per cent fortified with ragi flour and germinated ragi flour sample were $6.2 \pm 1.30,6 \pm 0.70,7 \pm 0.70$ and $7.4 \pm 0.54$, respectively. It was observed that mathris prepared with fortification of 30 per cent germinated ragi flour were the most acceptable and liked by the panel of members. The results of the analysis indicated that Ca content was 198.9, Fe was 2.19 and $\mathrm{P}$ was $92 \mathrm{mg} / 100 \mathrm{~g}$ in the control mathris. On the other hand, mathri fortified with 20 per cent and 30 per cent germinated ragi flour contained high content of $\mathrm{Ca}(329.0$ and $394.1 \mathrm{mg} / 100 \mathrm{~g}$, respectively). This shows that the germination increases the calcium content in ragi. Regarding the level of iron, fortification of mathris with non-germinated ragi flour at 20 per cent and 30 per cent levels increased the iron content. Iron was found to be 2.68 and $4.06 \mathrm{mg} / 100 \mathrm{~g}$ in the non-germinated ragi flour fortified mathris. While, in the mathris that were fortified with germinated ragi flour at 20 per cent and 30 per cent levels had comparably higher iron content. Level of phosphorus in non-germinated ragi flour fortified mathris (20\% and 30\% levels) had 96 and $148 \mathrm{mg} / 100 \mathrm{~g}$ and germinated ragi flour had phosphorus 172 and $256 \mathrm{mg} / 100 \mathrm{~g}$.
\end{abstract}

Key Words : Ragi, Germinated ragi flour, Fortified mathri, Organoleptic evaluation, Mineral content

How to cite this article : Gautam, Anamika and Sati, Vandana (2019). Development of value added product with ragi and analyze the mineral content. Food Sci. Res. J., 10(2):149-153, DOI : 10.15740/HAS/FSRJ/10.2/149-153.Copyright@ 2019: Hind Agri-Horticultural Society.

Vandana Sati, Department of Food Science and Nutrition, College of Community and Applied Sciences, Maharana Pratap University of Agriculture and Technology, Udaipur, (Rajasthan) India 